\title{
Design and Key Measurement Error Analysis of Performance Parameters Test System for Hydraulic Servo System
}

\author{
Chi $\mathrm{He}^{1,2, *}$, Guangling Dong ${ }^{2}$, Qiang $\mathrm{Li}^{2}$ and Mingyue $\mathrm{Sun}^{2}$ \\ ${ }^{1}$ School of Mechatronic Engineering, Changchun University of Science and Technology, Changchun Jilin, China \\ ${ }^{2}$ Dept. of Test Technology, Baicheng Ordnance Test Center of China, Baicheng Jilin, China \\ *Corresponding author
}

\begin{abstract}
Hydraulic servo system (HSS) is a kind of automatic control system widely used in fields of industry, aerospace, military, etc., whose performance directly influences whether the controlled object meet control requirements. In this paper, the composition and working principle of performance parameter test system for hydraulic servo system were introduced, and the error source from measuring rotation angel of gun barrel with electric cylinder displacement and its error compensation method were analyzed emphatically. Simulation experiment results show that the improved performance parameter test system meets the operating requirements of customer.
\end{abstract}

Keywords-hydraulic servo system (HSS); performance parameters test; electric cylinder; measurement error analysis $t$

\section{INTRODUCTION}

HSS is a kind of automatic control system using hydraulic power, whose output quantities as displacement, velocity, and force could reflect the variation of input value automatically and rapidly with high accuracy and steadiness. HSS takes on the following features as large-scale step-less speed regulation in working process, small volume and movement inertia, light weight, good dynamic performance in transmission gear, stable movement with zero clearance, and convenience in realizing automatic work cycle and overload protection [1]. So, HSS is widely used in fields of industry, aerospace, defense and military. HSS researched in this paper are used in gun's operation control of armored vehicle, also known as gun control system (GCS). In type approval test of GCS, forces with specified size and form are required to exert on gun barrel to measure some parameters, meanwhile movement parameters of the gun and turret need to be measured. Thus, we can calculate performance parameter of GCS to provide the basis for its approval test [2]. These parameters mainly include backlash value, friction moment, trimming moment, stiffness, etc., which all need force exerted on gun barrel.

As high and new technologies are widely used in weapons system, performance of GCS improves dramatically. In order to improve measuring accuracy of tank GCS test, design of measuring system must consider the smoothness, rapidity, and precision in force application as well as the angle measurement accuracy [3]. The researched test system in this paper takes on high performance electric cylinder as action element, high precision force transducer and displacement sensor as feedback element, which uses force application and displacement feedback as double closed-loop control method to ensure security and realize no overshoot control of force application system. Worldwide engineering staffs have taken in-depth and far-ranging studies on working principle and applications of electric cylinder. Dr. Chen and his research group studied the characteristics and performance requirements of electric cylinder and some of the electric cylinder application, and discussed the development trend of electric cylinder [4]. Dr. Yang from Chongqing University [5], and senior engineer Liang in Aviation University of Air Force [6] analyzed measuring method and error compensation method of electric cylinder respectively. Research group of professor Yang from Zhejiang University of Technology [7] studied the application of electric cylinder in earthquake vibration simulation, and got some useful results.

In this paper, we design a performance parameters test system for HSS, and study the major factors influencing measuring accuracy with emphases. Besides, error compensation model is built, whose effectiveness is validated with simulation to determine the effect of error compensation.

\section{Design OF Test System}

\section{A. System Composition}

Performance parameters test system for HSS is designed as an electric cylinder based automatic measuring and control system. Its system sketch map is shown in Figure 1.

Performance parameters test system for HSS is composed of three parts. The first is computer system used for test parameter setting, process monitoring, data processing, and test results storage. The second is force exertion control system, including force measuring and control interface circuit, force sensor, driving motor and electric cylinder. The third is displacement control system, including displacement control interface circuit, position sensor, and laser range finder, which takes tank gun barrel as load.

In Figure 1, real lines with single arrow are electric signal transmission lines, solid double lines are mechanical connection, solid double line with single arrow means mechanical contact between force application indenter and gun barrel. 


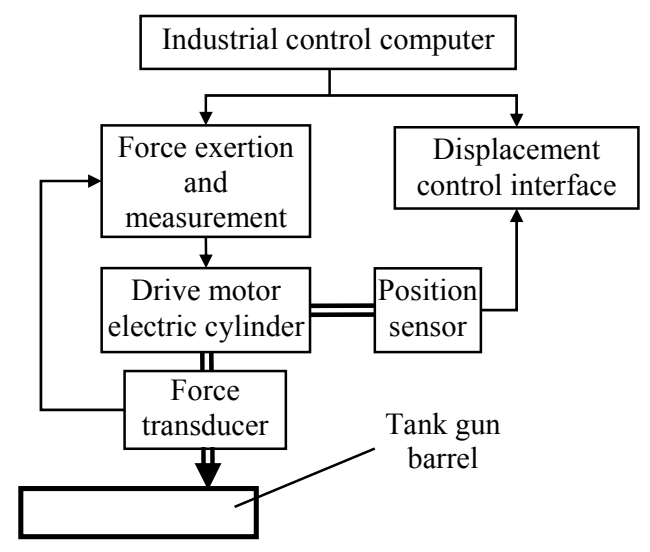

FIGURE I. STRUCTURE OF PERFORMANCE PARAMETERS TEST SYSTEM FOR HSS.

\section{B. Working Principles}

In performance test for GCS of armored vehicle, the test system needs to accomplish three basic missions. The first one is to exert force with specified form and magnitude on gun barrel to measure parameters of backlash, stiffness, etc. The second is to drive gun barrel to move with given uniform speed, which used for measuring required force magnitude to calculate parameters of friction moment, unbalanced moment, etc. The last is to realize security control of test system and no overshoot force application control.

Before test, operators set basic parameters on computer, which mainly include name and type of weapon systems under test, exerted force value and its safety limit, measuring range, test time and information of operating staffs. During test, test system first accomplishes system status checking, and reports self-checking results. As all status being normal, test system automatically accomplishes force application, force measurement, and angular measurement. Then, it accomplishes calculation of performance parameters according to given formula. In the end, it outputs test results and makes test data storage.

\section{SYSTEM ERROR ANALYSIS AND SIMULATION VALIDATION}

\section{A. Measurement of Key Parameters}

In performance parameter test of GCS, the measured values mainly include angular displacement, angular velocity and different kinds of force moment. All these parameters are indirect measured values, whose final results are calculated with appropriate formula through measuring relative displacement of gun muzzle on target plate. According to regulations of national military standard, representative angular displacement parameter can be calculated from (1).

$$
\theta_{1}=0.96 \frac{d}{R}
$$

Where, $\theta_{1}$ is rotational angle of gun, mil $\left(6000 \mathrm{mil}=360^{\circ}\right)$; $d$ is relative displacement of gun muzzle on target plate, $\mathrm{mm} ; R$ is distance from rotation center of gun turret to gun muzzle, m; and 0.96 is unit conversion factor of degree to radian.

It can be seen from (1) that measuring error for performance parameter of GCS mainly caused by two reasons, the first is adoption of approximation formula in measurement of angular displacement; and the second is measurement error of $d$ and measurement error of $R$ in length measurement.

\section{B. Simulation of Calculation Formula Error}

In this part, the measuring error caused by approximation formula is analyzed. Figure 2 shows the schematic diagram for angular displacement measurement of gun barrel.

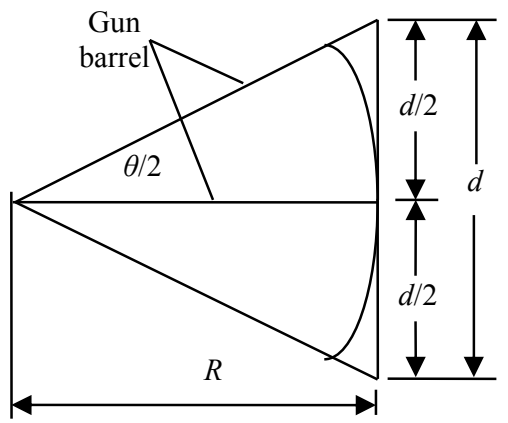

FIGURE II. SCHEMATIC DIAGRAM FOR ANGULAR DISPLACEMENT MEASUREMENT OF GUN BARREL.

Equation (2) is precise trigonometric function formula for calculating rotational angle of gun barrel.

$$
\theta_{2}=\frac{6000}{\pi} \arcsin \frac{d}{2000 R}
$$

Measuring error $\Delta \theta$ brought by approximation formula can be calculated with (3), while relative error $\delta \theta$ can be calculated by (4).

$$
\Delta \theta=\theta_{1}-\theta_{2}
$$

$$
\delta \theta=\Delta \theta / \theta_{2}
$$

Taking elevation angle for GCS of certain type of armored vehicle as an example, the influence of $d$ on measurement accuracy is calculated with Matlab program, whose results are listed in Table 1. The calculated curve is shown in Figure 3. Angle unit of the calculated results is converted from radian to degree.

It can be seen from calculated results that relative error brought by computing formula specified in national military standard remains a stable and decreasing trend in measuring range. Error values decrease with $d$, with a maximal relative error not exceeding $0.6 \%$. 
TABLE I. INFLUENCE OF D ON MEASURING ECCURACY

\begin{tabular}{|c|c|c|c|c|}
\hline $\begin{array}{c}\boldsymbol{d} \\
(\mathbf{m m})\end{array}$ & $\begin{array}{c}\boldsymbol{\theta} \\
(\boldsymbol{})\end{array}$ & $\begin{array}{c}\boldsymbol{\theta}^{\prime} \\
\left({ }^{\circ}\right)\end{array}$ & $\begin{array}{c}\Delta \boldsymbol{\theta} \\
\left({ }^{\circ}\right)\end{array}$ & $\begin{array}{c}\Delta \boldsymbol{\Delta} / \boldsymbol{\theta}^{\prime} \\
(\mathbf{\%})\end{array}$ \\
\hline 1.0 & 0.0230 & 0.0229 & 0.0001 & 0.5310 \\
\hline 5.0 & 0.1152 & 0.1146 & 0.0006 & 0.5309 \\
\hline 10.0 & 0.2304 & 0.2292 & 0.0012 & 0.5309 \\
\hline 20.0 & 0.4608 & 0.4584 & 0.0024 & 0.5307 \\
\hline 40.0 & 0.9216 & 0.9167 & 0.0049 & 0.5299 \\
\hline 85.0 & 1.9584 & 1.9482 & 0.0102 & 0.5261 \\
\hline 175.0 & 4.0320 & 4.01152 & 0.0205 & 0.5104 \\
\hline 260.0 & 5.9904 & 5.9614 & 0.0290 & 0.4856 \\
\hline 350.0 & 8.0640 & 8.0280 & 0.0360 & 0.4488 \\
\hline 435.0 & 10.0224 & 9.9821 & 0.0403 & 0.4039 \\
\hline
\end{tabular}

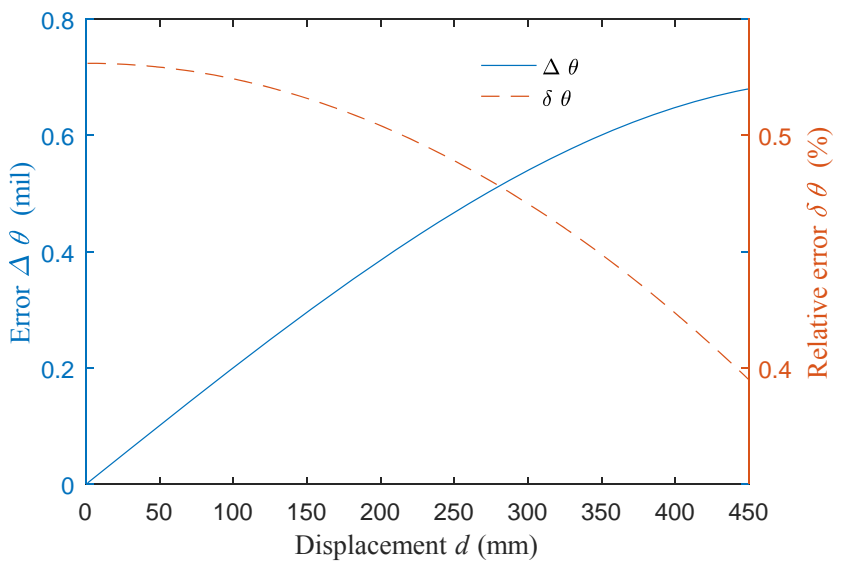

FIGURE III. INFLUENCE CURVES OF $d$ ON MEASUREMENT ACCURACY.

With fixed $d=130 \mathrm{~mm}$, the influence of $R$ on measurement accuracy is calculated in a Matlab program, whose results are listed in Table 2. The calculated curve is shown in Figure 4. Angle unit of the calculated results is converted from radian to degree.

TABLE II. INFLUENCE OF $R$ ON MEASURING ECCURACY

\begin{tabular}{|c|c|c|c|c|}
\hline $\begin{array}{c}\boldsymbol{R} \\
(\mathbf{m})\end{array}$ & $\begin{array}{c}\boldsymbol{\theta} \\
\left({ }^{\circ}\right)\end{array}$ & $\begin{array}{c}\boldsymbol{\theta}^{\prime} \\
\mathbf{(}^{\circ}\end{array}$ & $\begin{array}{c}\Delta \boldsymbol{\theta} \\
\left({ }^{\circ}\right)\end{array}$ & $\begin{array}{c}\Delta \boldsymbol{\Delta} / \boldsymbol{\theta}^{\prime} \\
\mathbf{( \% )}\end{array}$ \\
\hline 2.0 & 3.7440 & 3.7249 & 0.0191 & 0.5133 \\
\hline 3.0 & 2.4960 & 2.4830 & 0.0130 & 0.5231 \\
\hline 4.0 & 1.8720 & 1.8622 & 0.0098 & 0.5265 \\
\hline 5.0 & 1.4976 & 1.4897 & 0.0079 & 0.5281 \\
\hline 6.0 & 1.2480 & 1.2414 & 0.0066 & 0.5290 \\
\hline 2.0 & 3.7440 & 3.7249 & 0.0191 & 0.5133 \\
\hline
\end{tabular}

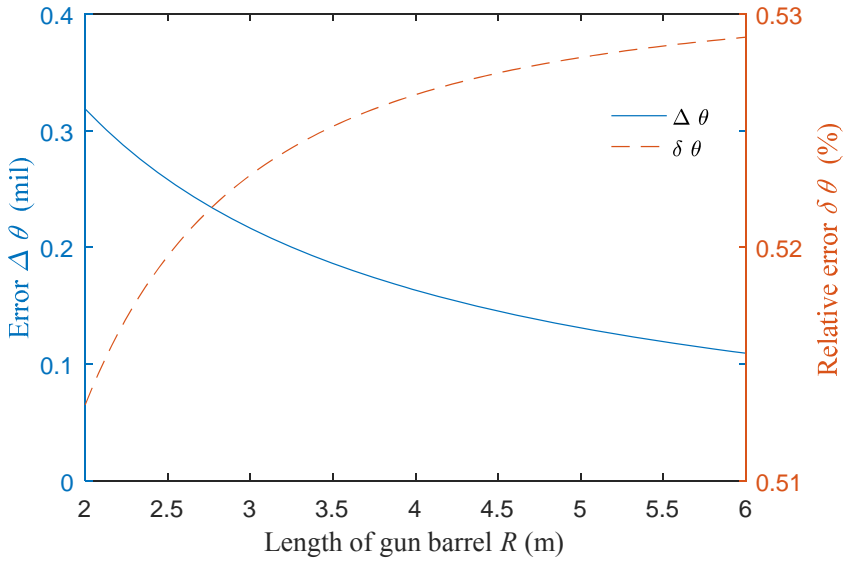

FIGURE IV. INFLUENCE CURVES OF $R$ ON MEASUREMENT ACCURACY.

Variation of $R$ has little influence on relative measurement error; relative error is within $0.016 \%$ in measuring range. So, there is no need to consider the influence of this parameter in the design of measurement system.

\section{System Measuring Error Calculation}

Taking stiffness measuring of GCS as example, extreme error of different direct measuring values is analyzed. Equation (5) is an computation formula for upward stiffness measuring of GCS.

$$
R_{\mathrm{u}}=\frac{F \times L}{\theta_{\mathrm{u}}} .
$$

Where, $R_{\mathrm{u}}$ is upward stiffness of GCS, N.m/mil; $\theta_{\mathrm{u}}$ is rotational angle of gun in upward movement under force application, mil; $F$ is the specified force exerted on gun muzzle, $\mathrm{N} ; L$ is distance from force point to gun trunnion, $\mathrm{m}$.

In design of test system, extreme error for different direct measurement values should be assigned according to the worst condition in measuring process. Namely, taking absolute values of error propagation coefficients to make calculation, whose computing formula is shown in (6).

$$
\Delta R_{\mathrm{u}}=\left|\frac{L}{\theta_{\mathrm{u}}}\right| \times \Delta F+\left|\frac{F}{\theta_{\mathrm{u}}}\right| \times \Delta L+\left|\frac{F \times L}{\theta_{\mathrm{u}}^{2}}\right| \times \Delta \theta_{\mathrm{u}} .
$$

Taking stiffness index for certain type of GCS as example, $R_{\mathrm{u}}=620 \mathrm{Nm} / \mathrm{mil}$, the required force value is $F_{\mathrm{G}}=145 \mathrm{~N}$, distance from force point to gun trunnion $L=6.00 \mathrm{~m}$, rotational angle of gun under force application can be worked out through abovementioned indices as $\theta=1.403$ mil. Measuring error of stiffness occupies $1 \%$ of measured value, i.e., $\Delta R_{\mathrm{u}}=6.2 \mathrm{Nm} / \mathrm{mil}$. From (6), we get

$$
6.20=4.276 \Delta F_{\mathrm{G}}+103.350 \Delta L+441.981 \Delta \theta_{\mathrm{u}} .
$$

Calculating force application and measurement errors $\left(\Delta F_{\mathrm{G}}\right)$ respectively on $0.5 \%, 0.1 \%$, and $0.05 \%$ of force application 
value, and taking measuring error $\Delta L$ of distance $L$ as $1 \mathrm{~mm}$, the calculated results for extreme errors of three direct measured quantities are shown in Table 3.

\section{TABLE III. EXTREMUM ERROR DATA OF DIRECT MEASURE PARAMETERSY}

\begin{tabular}{|c|c|c|c|}
\hline $\begin{array}{c}\text { Sequence } \\
\text { number }\end{array}$ & $\begin{array}{c}\text { Force } \\
\text { exertion and } \\
\text { measurement } \\
\text { error } \Delta \boldsymbol{F}_{\mathbf{G}} \\
\text { (N) }\end{array}$ & $\begin{array}{c}\text { Measuring } \\
\text { error of } \\
\text { distance } \Delta \boldsymbol{L} \\
\mathbf{( m )}\end{array}$ & $\begin{array}{c}\text { Measurement } \\
\text { error of angular } \\
\text { displacement } \boldsymbol{\Delta} \boldsymbol{\theta} \\
\text { (mil) }\end{array}$ \\
\hline 1 & 0.725 & 0.001 & 0.0068 \\
\hline 2 & 0.145 & 0.001 & 0.0124 \\
\hline 3 & 0.072 & 0.001 & 0.0131 \\
\hline
\end{tabular}

It can be seen from Table 3 that the errors of subsystems have inter-relational constraint among each other when total measuring error of system is determined. But, the subsystems have different effects on total measuring error owing to their different error propagation coefficients.

It takes little effect to improve overall measurement precision by increasing force measuring accuracy. While decreasing angle measurement error could be very effective to improve overall measurement precision of the system.

\section{CONCLUSIONS}

As a special kind of HSS, GCS has been widely used in driving guns of armored vehicle. In weapon systems' performance test of armored vehicles, indices as rotational angle of gun barrel, friction moment of gun, stiffness of hydraulic GCS, etc., need to be measured according to requirements of national military standards. Generally, there are three kinds of works for performance parameter test of HSS First, forces with specified magnitude and form are exerted on gun muzzle according to test requirement. Second, force application value is measured as feedback quantity of force control system and parameter computation value. Third, rotational angle of gun barrel is measured. On analyzing existing techniques of force application, force measuring, and angular measurement, electric cylinder is chosen as the kernel component of test system.

Based on analysis of angular measuring formula error and stiffness parameters measuring error given in national military standard, as well as the simulation results, we can get the following results:

- Error caused by angular measuring formula increase with $d$ value, yet the relative error remains a decreasing trend.

- In the measuring range, variation of $\mathrm{R}$ value has little influence on relative error of angular measuring, which can be neglected in design of test system.

- Magnitude of small angular measurement determines the precision of angular measurement sensor.

- In analysis of stiffness measuring error, angular error occupies more than $90 \%$ of measuring error.
Therefore, displacement measuring transducer selection of electric cylinder must be focused on in design of performance parameters test system for HSS.

\section{REFERENCES}

[1] T. Chang, Hydraulic Control System. Beijing: Tsinghua University Press. 2014 .

[2] T. Chen, Z. Yang, and C. He, "Study on the dynamic performance of a new force application system used in tank gun control system approval testing," in ACTA ARMAMENTII, 2007, vol. 28, pp.1507-1511.

[3] L. Zhou, G. Cao, C. He, G. Dong, and J. Wang, “ Design and Simulation Analysis of Exertion Control System Used in Gun Control System Test," 2010 IEEE International Conference on Mechatronics and Automation. Xi'an, China, August 4-7, 2010 (ICMA 2010), pp.747-750.

[4] C. Chen, S. Zhao, M. Cui, H. Cai and X. Li, "Study Status and Developing Trend of Electric Cylinder," in Mechanical Transmission, 2015 , vol. 39 no. 3, pp. 181-186.

[5] J. Yang, K. Liu, Z. Yang, and H. Che, "Design of a parameter measurement system for electric cylinder," in Journal of Chongqing University, 2015 , vol.38 no.4, pp. 31-37.

[6] J. Liang, Y. LU, Y. Wang, and F. Sun, "The Measurement and Compensation for Transmission Error of Electric Cylinder," in Microcomputer Information, 2010 , vol.26 no.12-2, pp. 182-183.

[7] J. Cao, J. Yang, Y. Ying, and X. Zhang, "Application of AC servo motor cylinder in vibration platform for earthquake simulation," in Experimental Technology and Management, 2011 , vol.28 no.4, pp. 6770. 